\title{
OBITUARY
}

\section{In memoriam: Anthony Jude Omolo Were}

\author{
Dr Anthony Were, a stalwart of the Kenyan and African \\ nephrology communities, died on 21 November 2020 at \\ the age of 64 .
}

When Anthony Were was elected President of the African Association of Nephrology (AFRAN) in September 2019, he embraced his new role with focus and vigour. It was his firm belief that AFRAN had a major role to play in improving the access to kidney care in Africa and he was determined to put African nephrology on the global map. Some of his notable achievements in the short time that he led AFRAN included establishing professional secretariat services, forming a guidelines committee that released a comprehensive guideline for nephrology service provision in the era of COVID-19, encouraging the formation of a vibrant Young Nephrologists Committee, and arranging the hosting of nephrology webinars (including joint sessions with the International Society of Nephrology) to an Africa-wide audience. He was also the force behind the African nephrologists' WhatsApp group where colleagues across the continent now easily exchange ideas and information.

Dr Were's commitment to excellence, selfless service and friendship was evident to all of us across Africa. He was a very active member of the Kenya Renal Association (KRA). Indeed, he chaired the annual scientific conferences of KRA in 2017 and 2019. Both these conferences were very successful in large part due to his able leadership. He also always made time to attend many other KRA activities including the annual World Kidney Day celebrations.

The role of Dr Were in the East African Kidney Institute cannot be overstated. As the founding deputy director of the institute, he spent a lot of time encouraging and mentoring trainees, including nephrology nurses and nephrology fellows. He was instrumental in developing the curricula for various courses offered by the institute. He was always available to his students, even in the COVID era, when he would moderate Zoom teaching sessions. It was his vision that the East African Kidney

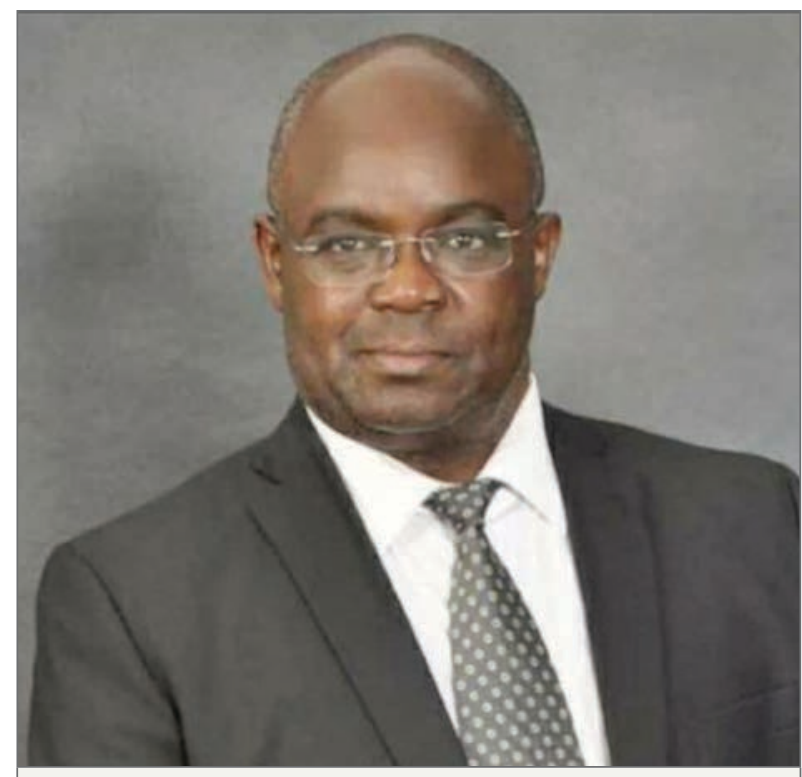

Anthony Were, 1956-2020.

Institute would grow to be a centre of excellence for nephrology training for medical professionals from Africa and beyond.

It is impossible to capture all that Anthony Were did for nephrology in Kenya and Africa. He was truly a champion for the provision of quality kidney care and his focus and energy saw him achieve remarkable milestones. He will surely be missed by all.

Condolences go to his family. May the Lord Almighty grant them the fortitude to bear this devastating loss. May his gentle soul rest in eternal peace.

\section{Ahmed Twahir \\ Kenya Renal Association}

